NBSIR $75-764$

\title{
Fin
}

\section{PYRAMIDAL SLIP AND BASAL \\ TWINNING IN ALUMINUM OXIDE}

B. J. Hockey

Inorganic Materials Division Institute for Materials Research National Bureau of Standards Washington, D. C. 20234

August, 1975

$$
\begin{aligned}
& \text { Hockei, B. J., Pyramidal slip on }\{11 \overline{3}\} \\
& \langle\overline{1} 100\rangle \text { and basal trinning in } \mathrm{Al}_{2} \mathrm{O}_{3} \text {, }
\end{aligned}
$$
(Proc. Symp. on Plastic Daforration of

Caramic MateriaIs, Pennsyivania State Univ., Uaiversity Perk, PA, JuIy 17-19, 1974), Chapter in Deformation of Cenamic

Materials, R. C. Bnadt and R. E. Tressler Ets., Sec. II, DD. 167-ح179 (3lenum Press, Niew York, NY, 1975).

This paper has been formerly published as follows:

(Proc. Symp. on Plastic Deformation of Ceramic Materials, Pennsylvania State Univ., University

Park, PA, July 17-19, 1974), Chapter in Deformation of Ceramic Materials, R. C. Bradt and R. E. Tressler, Eds., Sec. II, pp. 167-179 (Plenum Press, New York, NY, 1975).

Prepared for

Department of the Army

U. S. Army Research Office

Box CM

Duke Station

Durham, North Carolina

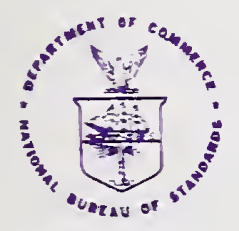

U.S. DEPARTMENT OF COMMERCE, Rogers C. B. Morton, Secretary 
NBSIR 75-764

\section{Pyramidal Slip and Basal Twinning in Aluminum Oxide}

B. J. Hockey

Inorganic Materials Division

Institute for Materials Research

National Bureau of Standards

Washington, D. C. 20234

August, 1975

This paper has been formerly published as follows:

(Proc. Symp. on Plastic Deformation of Ceramic

Materials, Pennsylvania State Univ., University

Park, PA, July 17-19, 1974), Chapter in Deformation

of Ceramic Materials, R. C. Bradt and R. E. Tressler, Eds.,

Sec. II, pp. 167-179 (Plenum Press, New York, NY, 1975).

Prepared for

Department of the Army

U. S. Army Research Office

Box CM

Duke Station

Durham, North Carolina 27706 
PYRAYIDAL SIIP ON $\{11 \overline{2} 3\}<\bar{I} I O O>$ AND BASAI TWINNING IN $\mathrm{Al}_{2} \mathrm{O}_{3}$

\author{
3. J. rockey \\ Institute for Materials Research \\ National Bureau of Stancarcis \\ Washington, D. C. 20234
}

\title{
PBSTRACT
}

Plastic aeformation of $\mathrm{AI}, \mathrm{O}_{3}$ by slip and twinning has been investigatea by examining the regions surrounding a microharaness incentation. using transmission electron microscopy (TEM). The results establish: (1) the occurrence of pyramical slig o. $\{11 \overline{2} 3\}\langle\bar{I} 100\rangle$, an: (2) the nature of basal twins in this material. The observations on basal twins, in particular, have lea to a completely different description for the twinning process, which is briefly cescribed.

\section{INTRODUCTION}

Previous ciservations by TEM [I] have shown that generalized plastic flow involving both siip and twinning occurs during the room temperature incentation of $\mathrm{Al}_{2} \mathrm{O}_{3}$. Indentation of various surface orientations--for example, by the placement of indertations within indivicual grains oł poiverystals--thus provides a simple experimental means for causing and subsequently stucying the possible modes of deformation by IE:?.

In this paper, the general usefulress of these techniques, which are particularly applicable to "hard, brittle materials" [2], is illustrated and specizic results (I) on the occurrence of pyranidal

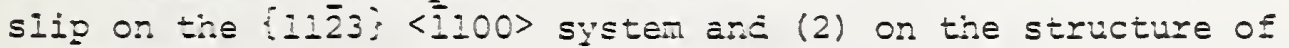
basal microtinins in $\mathrm{AI}_{2} \mathrm{O}_{3}$ are presentec. 


\section{EXPERIMENTAL DESCRIPTION}

The methods used in the initial specimen preparation, indentation, and the preparation of thinned electron microscope specimens have been previously published [1]. In the present study, the electron microscope was operated at an accelerating voltage of 200 $\mathrm{kv}$ and a double-tilt $\left( \pm 4^{\circ}\right)$ specimen holder was used to tilt the specimen to various two-beam conditions.

Al1 observations presented here were obtained from the region surrounding a 200 gram Vickers hardness indentation, made at room temperature within a single grain of sintered polycrystalline alumina. Fig. I is a sterographic projection ${ }^{*}$ onto the plane of the foil and shows that the normal to the original crystal surface was close to the $(11 \overline{2} 3)_{\text {pole. }}$ The other poles listed correspond to the various reflections used in the analysis of slip and twinning described in the following sections.

\section{RESULTS AND DISCUSSION}

$$
\text { A. Slip on }\{11 \overline{2} 3\}<\overline{1} 100>
$$

Observations on the indented specimen revealed numerous arrays of dislocations which extended from the indentation in various directions. Fig. 2 shows the configuration of dislocation found in one area. In this micrograph, the beam is nearly normal to the foil, and it is clear that the region contains arrays of short dislocation segments (E) situated on inclined planes that intersect the foil along $A-B$, together with long dislocation segments ( $S$ ) which are nearly parallel to $A-B$. The regions of dark contrast, $F$, are apparently faults which also intersect the foil along A-B. Although not apparent in this projected view, stereomicroscopy revealed that all of the isolated dislocations ( $S$ and $E$ ) lie on the same set of parallel planes, which is also the plane of the faults, F.

The presence of curved dislocations on parallel planes strongly suggests that the observed configuration is a result of slip.

\footnotetext{
*

Miller-Bravais indices corresponding to the structural unit cell $c / a=2.730$, are used throughout.

$* *$

Indices of corresponding reciprocal space vectors satisfy the refleating conditions: $-H+k+l=3 n ; h h \overline{2} h l:(l=3 n) ; h \bar{h} \circ l: h+l=3 n$, $\ell+2 \mathrm{n}[3]$.
} 


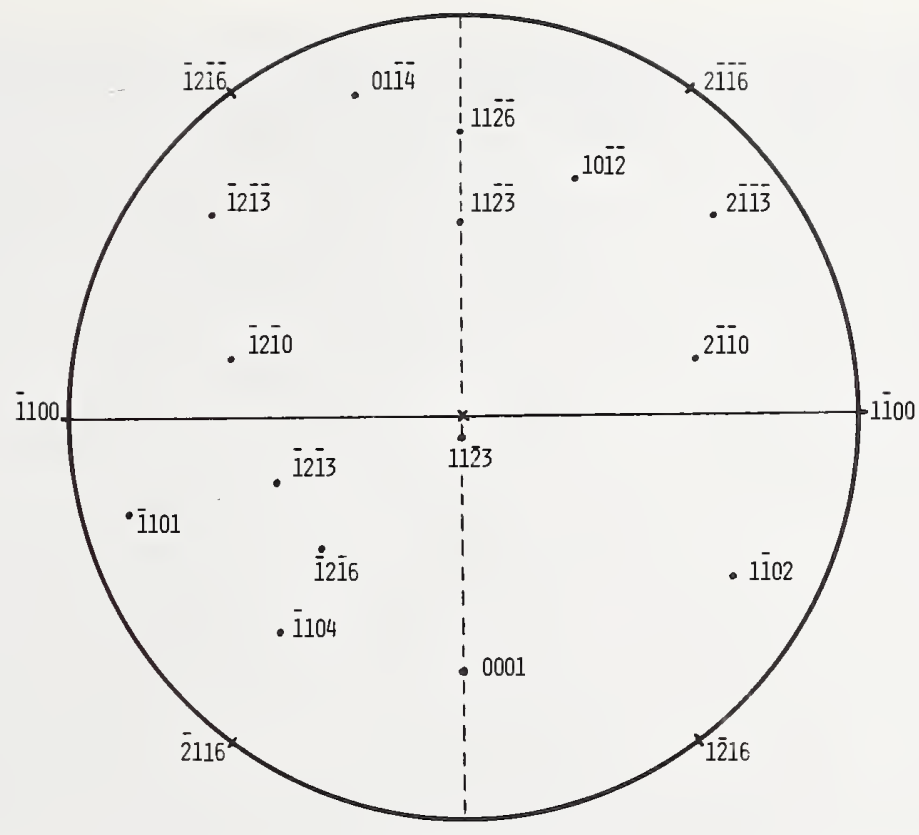

Figure 1. Stereographic projection normal to the indented specimen surface. With the exception of $11 \overline{2} 3$, all poles listed correspond to the variousreflections used in the analyses described in section 3.

This conclusion was confirmed by determining both the apparent slip plane and the Burgers vector of the isolated dislocations. The lack of direct evidence for the various slip systems proposed for $\mathrm{Al}_{2} \mathrm{O}_{3}$ [4], make it worthwhile to consider the details of the results.

(a) Slip Plane. With reference to Fig. 1, the intersection of the apparent slip planes and faults, F, with the surfaces of the foil was determined to be along [i1100]. Accordingly, the plane of the dislocations must belong to the [il100] zone, which is indicated by the dotted great circle in Fig. 1. Identification of this plane was then made by tilting the foil about [ $\overline{1} 100]$ until the dislocations and faults were edge-on (i.e. parallel to the electron beam). As shown in Fig. 3, this position of the foil was determined by electron diffraction to coincide with the $11 \overline{2} \overline{3}$ reflecting position.

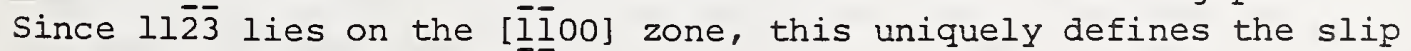
(and fault) plane as $(11 \overline{2} \overline{3})$. 


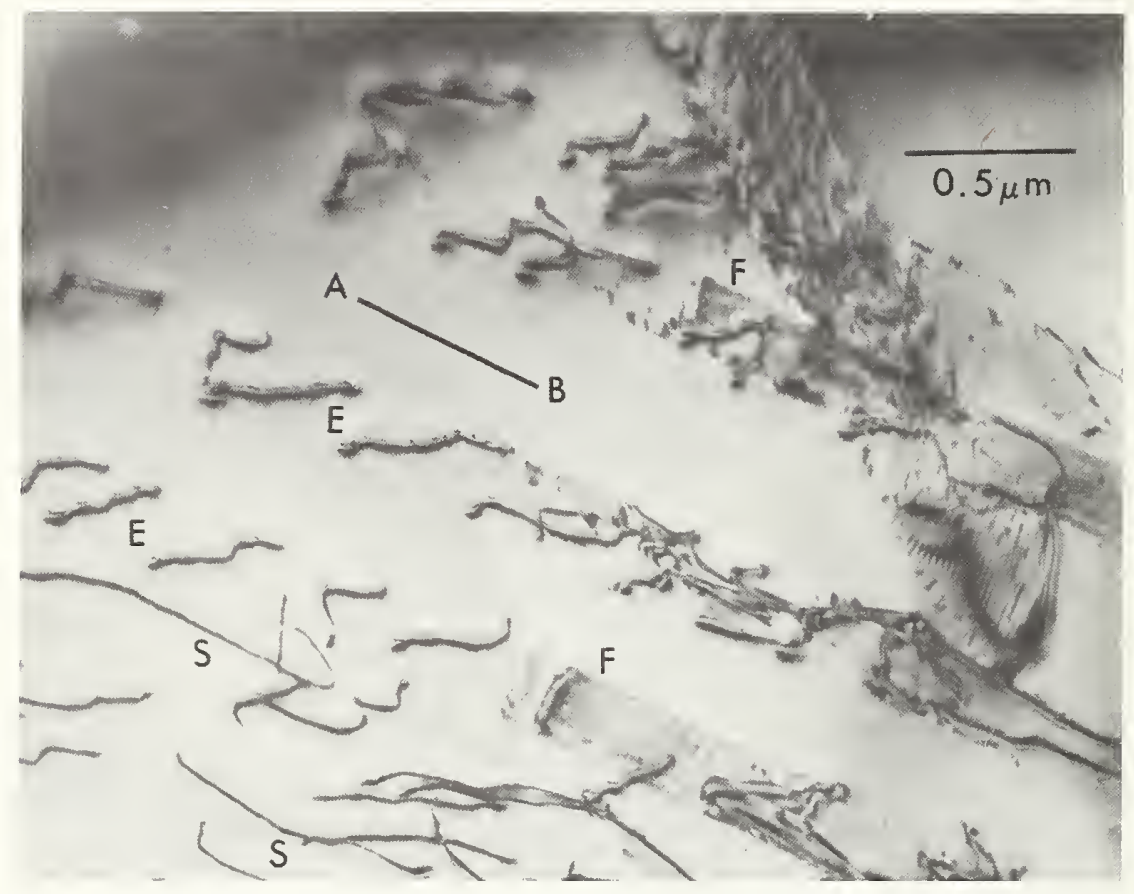

Figure 2. Arrays of dislocations associated with $200 \mathrm{~g}$ Vickers hardness indentation which were determined to be a result of slip on (11 $\overline{2} \overline{3})[\overline{1} 100]$. See text for description.

(b) Slip Direction. The region of Fig. 2 was examined under various two-beam reflecting conditions_(see Fig. 1) to determine the nature of the dislocation arrays on $(11 \overline{2} \overline{3})$. These observations confirmed that the isolated dislocations, $S$ and $E$, were total, slip dislocations. The nature of the faults, $F$, and their bounding partial dislocations also present on $(11 \overline{2} \overline{3})$, however, could not be clearly established.

As will be seen, the determination of the Burgers vector for the total dislocations was complicated by the fact that strong residual contrast was produced for nearly all of the reflections used. As a result, a unique solution for $\underline{b}$ could not be made solely on the basis of the $\bar{q} \cdot \underline{b}=0$ invisibility criterion, but instead required a lengthy comparison of the observed contrast with that expected for edge and screw dislocations of different Burgers vectors. $[5,6]$ All possible lattice vectors for the $\mathrm{Al}_{2} \mathrm{O}_{3}$ structure of reasonable magnitude (i.e. <12 A) were included in this compárisori. On the basis of this analysis which for the sake of brevity is not detailed here - the only reasonable agreement between observed and expected contrast was obtained for $\underline{B}=[\overline{1} 100]$. 


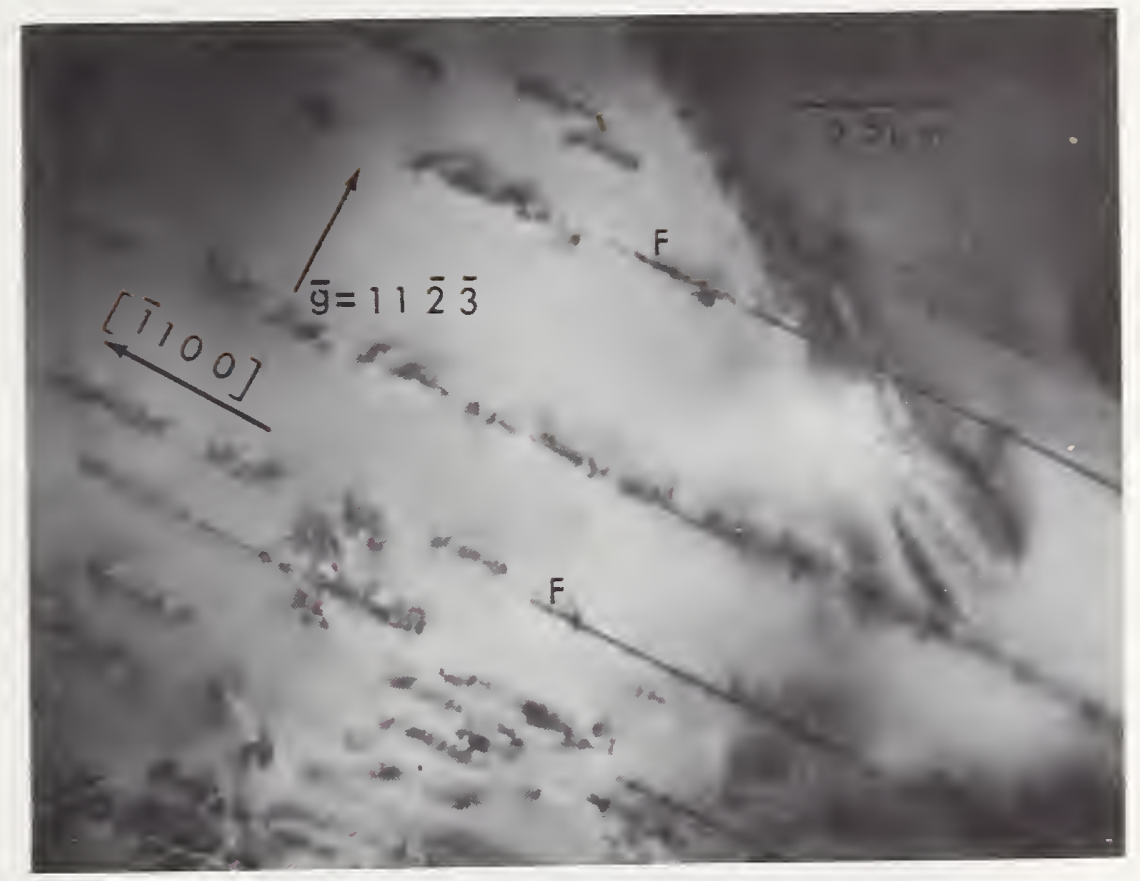

Figure 3. Dislocations and faults are seen "edge-on" with specimen tilted to the $11 \overline{2} \overline{3}$ reflecting position.

In agreement, comparison of Figs. $4 a$ and $4 b$ with Fig. 3 shows that the long dislocation segments (S) lying close to [II00] are either_out of contrast or show only a weak residual contrast for $\bar{g}=11 \overline{2} \overline{3}$ and $\bar{g}=11 \overline{2} \bar{b}$. Under both conditions, $\bar{g} \cdot[\overline{1} 100]=0$ and it can be concluded that these dislocations are screw or near screw segments with $b=[\bar{l} 100]$. From their line orientation, those dislocations which are steeply inclined to the foil (E) appear to correspond to edge or near edge [Il00] dislocation segments. Although these dislocations are in contrast, particularly in Fig. $4 b$, the nature of the line contrast is characteristic of that expected for edge dislocations when $\bar{g} \cdot \underline{b}=0$, but $m=1 / 8 \bar{g} \cdot \underline{b} \times \underline{u} \geqslant 0.2$, where $\underline{u}$ is a unit vector tangent to the dislocation line (see e.g. [5] and [6]). Since $\underline{b} x \underline{\underline{n}}$ is simply a vector of magnitude $|b|$ along the normal to the $(11 \overline{\overline{2}} 3)$ slip planes, this expression for $\mathrm{m}$ can be reduced to:

$$
1 / 8|g|_{\text {hkil }}|b| \cos \theta=1 / 8 \frac{|b| \cos \theta}{d_{h k i l}}
$$


for pure edge dislocations, where $\theta$ is the angle between $\bar{g}_{h k i l}$ and the ( $(1, \overline{2} \overline{3})$ pole. Using this expression, calculated values of

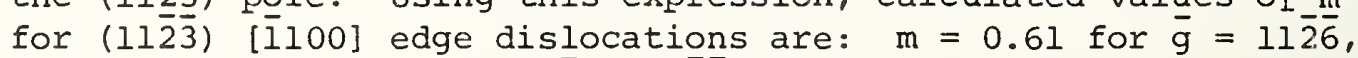
Fig. $4 b$, and $m=0.49$ for $\bar{g}=11 \overline{2} \overline{3}, \mathrm{Fig} .4 \mathrm{a}$. These values are quite large and the strong contrast observed experimentally is expected.
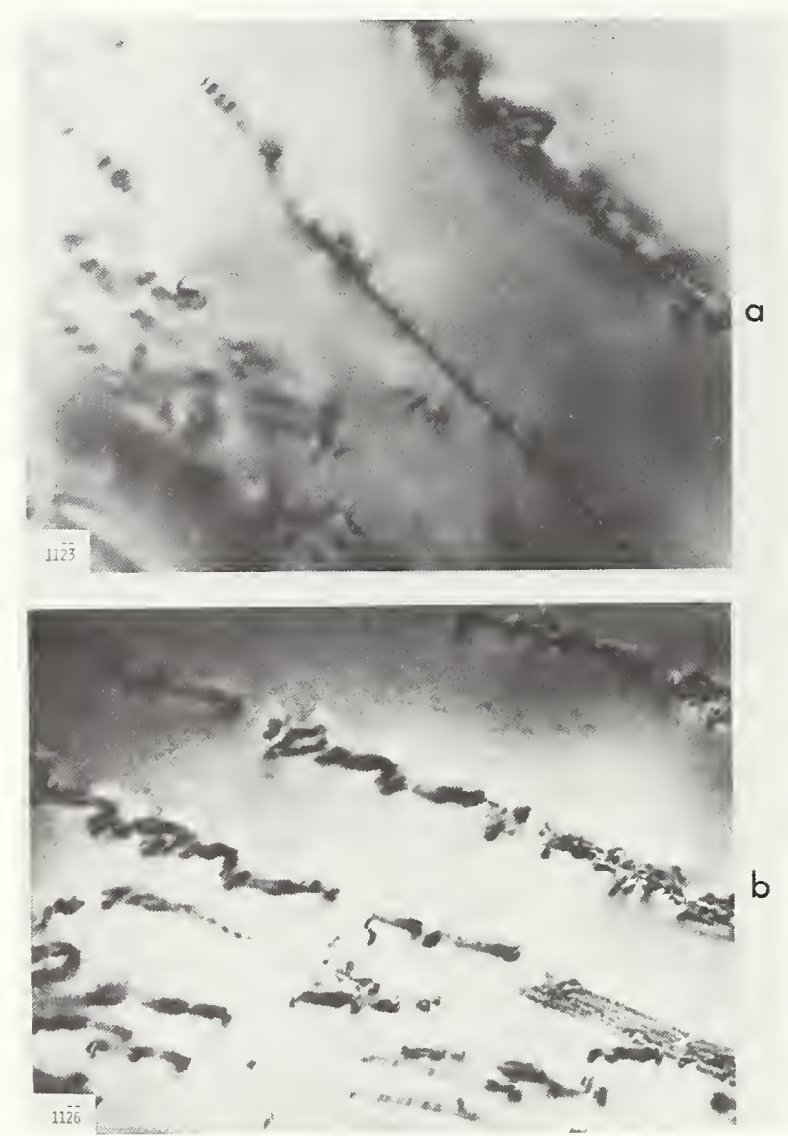

Figure 4. Image contrast of dislocations on ( $11 \overline{2} \overline{3}$ ) planes produced for: a) $\bar{g}=11 \overline{2} \overline{3}$ and b) $\bar{g}=11 \overline{2} \overline{6}$. For both reflections,

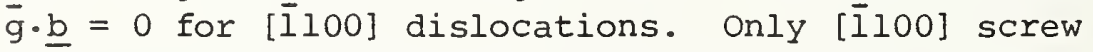
segments are invisible; edge segments show strong contrast due to large values of $\mathrm{m}=1 / 8 \overrightarrow{\mathrm{g}} \cdot \underline{\mathrm{b}} \times \underline{\mathrm{u}}$.

In further agreement, strong double line contrast for both screw (S) and edge (E) segments was observed in reflections for which $\bar{g} \cdot[\bar{l} 100]=2$ at $s=0$ (i.e., at the Bragg reflecting posi-. tion). This is illustrated in Fig. 5, where $\bar{g}=1 \bar{l} 02$. 


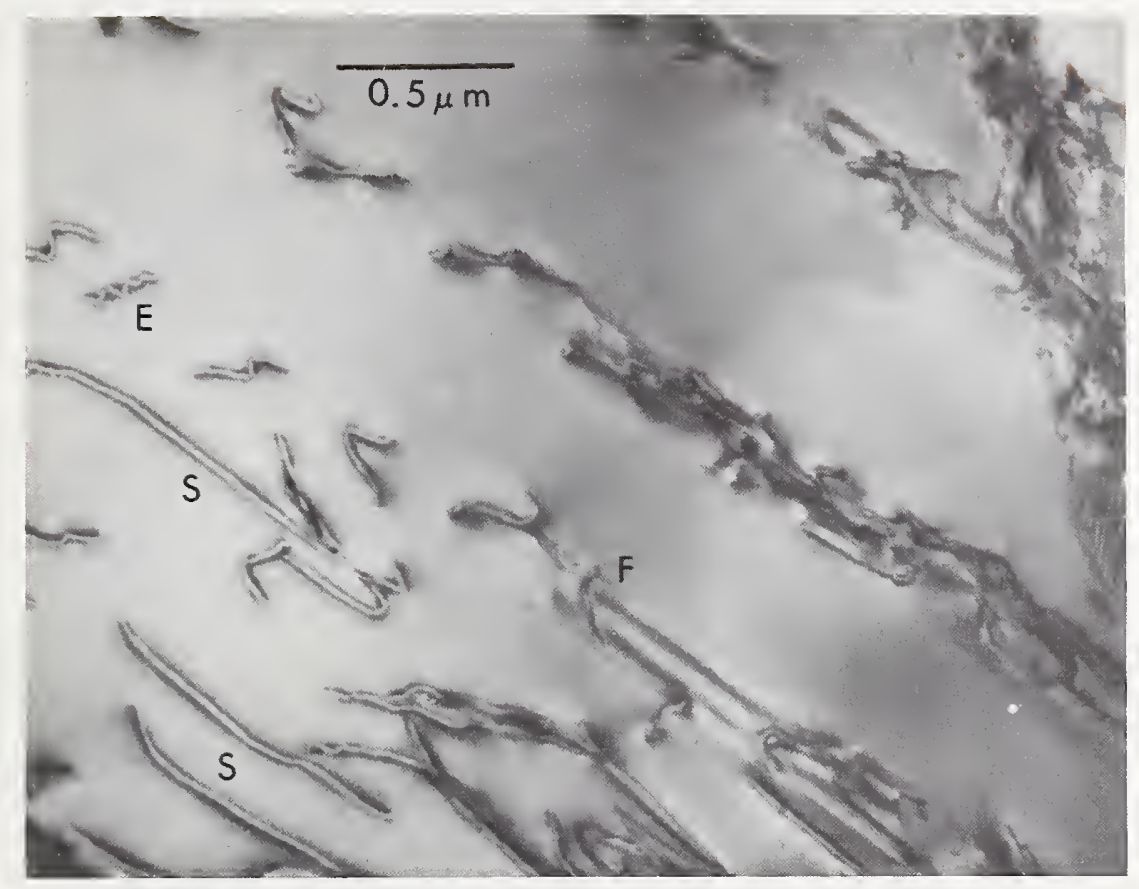

Figure 5. Edge and screw [ī100] dislocation segments in double image contrast $(\bar{g} \cdot \underline{b}=2)$ for $\bar{g}=1$ I02 at $s=0$.

The present results thus provide clear evidence that slip on $\{11 \overline{2} 3\}\langle 1100\rangle$ occurs during the room temperature indentation of $\mathrm{Al}_{2} \mathrm{O}_{3}$. As yet, no explanation can be given regarding either the choice or activity of this particular system. In particular, it should be noted that 1/3 [0111] and not [I100] corresponds to the shortest lattice vector in (1123). Conceivably, the extremely high stresses developed during point loading may result in the activation of certain slip systems which may never be energetically favorable modes of bulk deformation under uni- or bi-axial loading. The assumption then that $\{1 \overline{1} \overline{2} 3\}<\overline{1} 100\rangle$ slip occurs during the high temperature bulk deformation of $\mathrm{Al}_{2} \mathrm{O}_{3}$ cannot be made solely on the basis of these results. However, KlassenNeklyudova et al. [7] have reported impurity segregation along $\{1123\}$ planes in ruby after deformation above $1850^{\circ}$. The present results, thus, appear to justify their conclusion that these bands 
are the result of slip. In addition, the present observations provide the first positive identification of glissile <lo $\bar{l} 0\rangle$ dislocations in $\mathrm{Al}_{2} \mathrm{O}_{3}$, which until now, could only be inferred from etch pits or the macroscopic displacements associated with $\{1 \overline{2} 10\}<10 \bar{l} 0>$ slip $[8,9,10]$.

\section{B. Basal Twinning}

Unlike $\{11 \overline{2} \overline{3}\}<\bar{I} 100>$ slip, there is ample evidence for deformation twinning on $\{0001\}[11,12,13]$. The macroscopic elements of basal twinning-first determined by morphological examination and later confirmed by $\mathrm{x}$-ray diffraction-are known to be:*

$$
\begin{aligned}
& k_{1}=(0001) ; \sigma_{1}=\langle 10 \overline{1} 0\rangle \\
& k_{2}=\{10 \overline{1} 1\} ; \sigma_{2}=\langle\overline{1} 012\rangle \\
& s=0.635
\end{aligned}
$$

Crystallographically, twinning on (0001) can be described hy a rotation of $180^{\circ}$ about [0001], which requires that the macroscopic

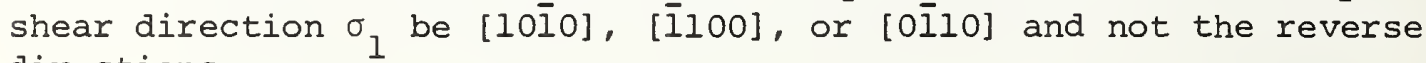
directions.

However, as pointed out by Kronberg, [14] uniform shear displacements along the observed twinning shear direction, $\sigma_{1}$, cannot possibly lead to a twinned structure. As a consequence, Kronberg proposed a rather complicated shearing mechanism involving the synchronized motions of "quarter-partial" twinning dislocations.

In this section, the structure of basal microtwins, as determined by TEM, is presented. The results identify the actual displacements associated with the twinned structure and have led to the development of a completely different description of the twinning process.

Figure 1 agains specifies the orientation of the indented specimen which contained numerous thin lamallar regions that often extended far beyond the zone of intense slip deformation. The identification of these lamallae as basal microtwins was readily established by selected area diffraction and the contrast observed under different diffracting conditions, Figs. $6 \mathrm{a}$ and $6 \mathrm{~b}$. Typically, these twins were quite thin $(\leq 2 \mu \mathrm{m})$ and essentially wedge-shaped with arrays of dislocations present within the twin-matrix boundary. These features are best illustrated in Fig. $6 \mathrm{c}$, which shows the same twin viewed edge-on. Here the twin boundaries are delineated

*It is important to emphasize that indices based on the true structural cell are used here. 
by the residual contrast associated with the boundary dislocations. Previous observations [15] on basal twins produced by indentation or surface grinding have revealed similar characteristics.

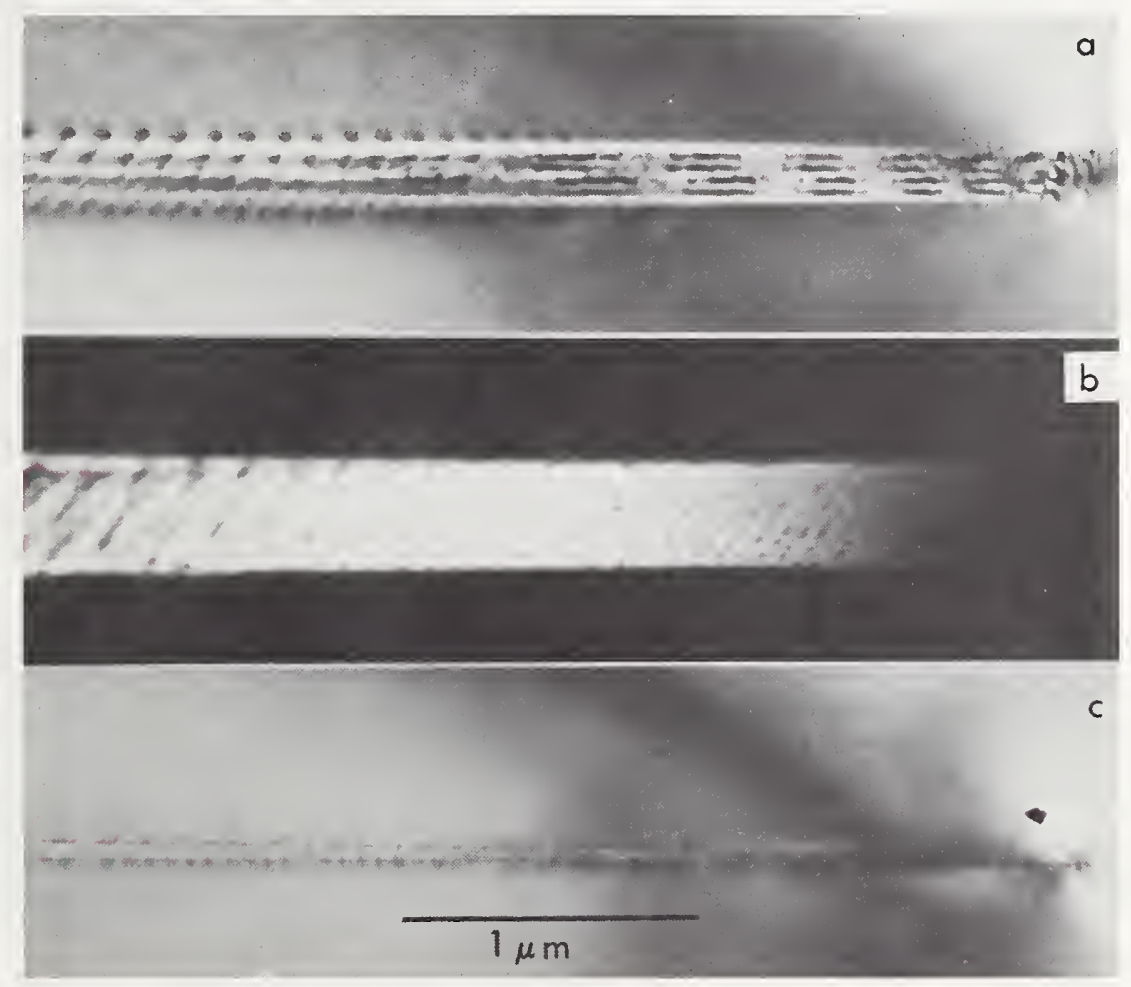

Figure 6. Basal microtwin under various diffracting conditions:
a) Bright field $\bar{g}=(0 \bar{l} 14)$ $\bar{g}=(10 \bar{l} 4)_{\text {twin' }}$
c) Bright field $\bar{g}=000.12$.

In the present study, the peculiar nature of the twin boundaries was established by unambigously determining the Burgers vectors of the boundary dislocations by application of the $\bar{g} \cdot \underline{b}=0$ invisibility criterion [5]. The essential results are contained in Figs. 7a-f, which show that, for this orientation, one face of the wedge boundary contains only $\pm[10 \bar{l} 0]$ dislocations, while the other face contains only $+[0 \bar{l} l 0]$ dislocations. Since similar contrast is observed at the points where the dislocations emerge from the foil, the dislocations within each face must be of the same sign. Although the magnitude of $\underline{b}$ was not determined, it can be shown that the boundary dislocations cannot be actual twinning partials, but instead must correspond to accommodation dislocations. 

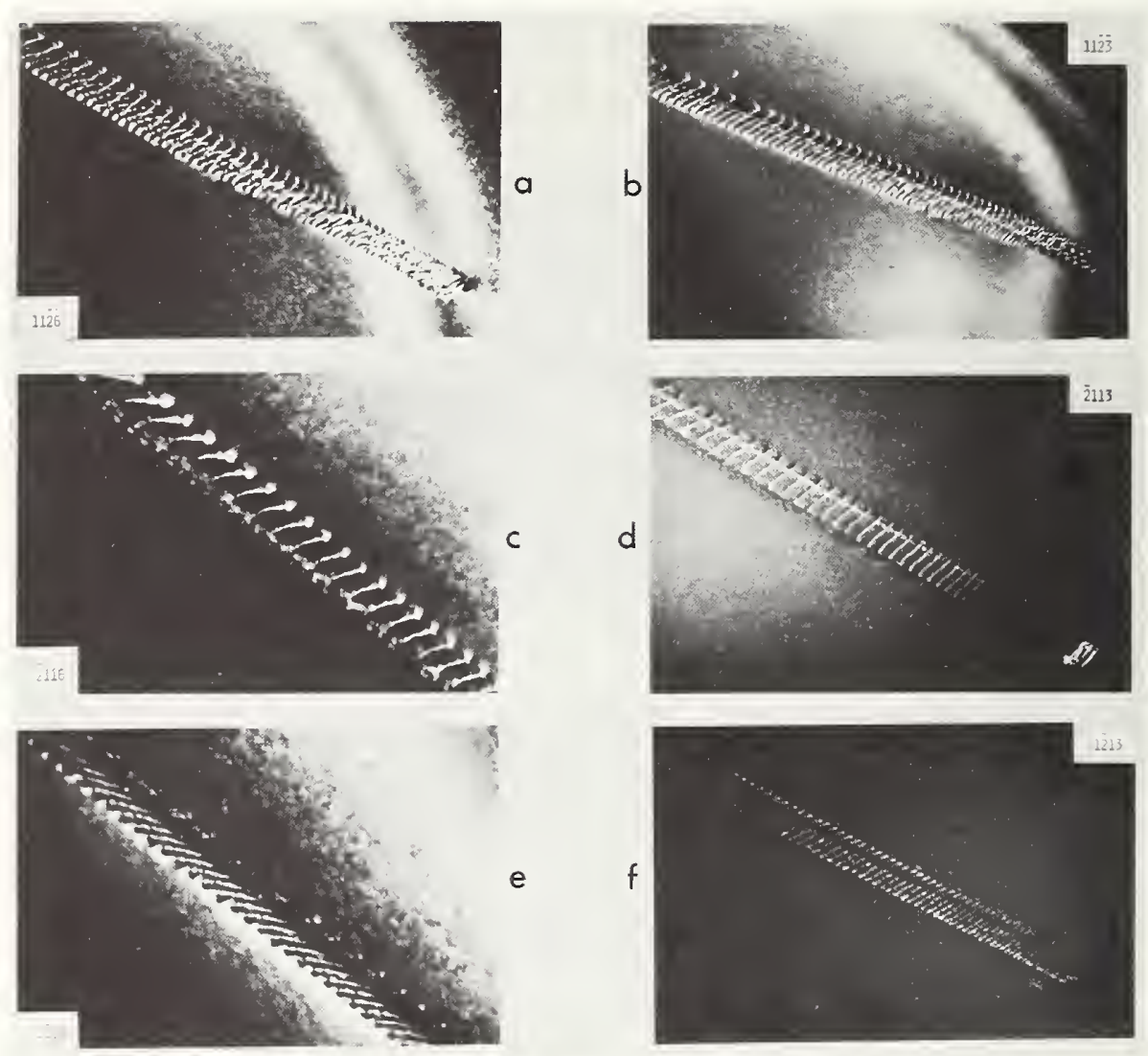

Figure 7. Basal twin boundary dislocations in different diffracting conditions. Dislocations in both faces of wedge-shaped twins are in contrast for a) $\bar{g}=11 \overline{2} \overline{6}$ and b) $\bar{g}=11 \overline{2} \overline{3}$. Dislocations in one face are invisible for c) $\bar{g}=\overline{2} 116$

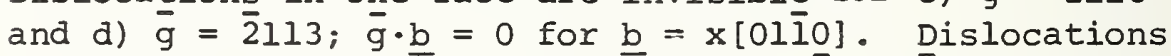
in opposite face are invisible for e) $\bar{g}=1 \overline{2} 16$ and $\mathrm{f}$ ) $\bar{g}=1213 ; \bar{g} \cdot \underline{b}=0$ for $\underline{b}=x[10 \overline{1} 0]$.

For the purposes of discussion, it is assumed that the unequal densities of dislocations present within the two boundaries simply indicatesthat the boundaries are not equally inclined to (0001) the subtended angle at the tip was too small (>20 in Fig. 6c) to allow experimental verification. Fig. 8a, thus, schematically represents the configuration of boundary dislocations at the tip of an ideal fully symmetric basal twin. 


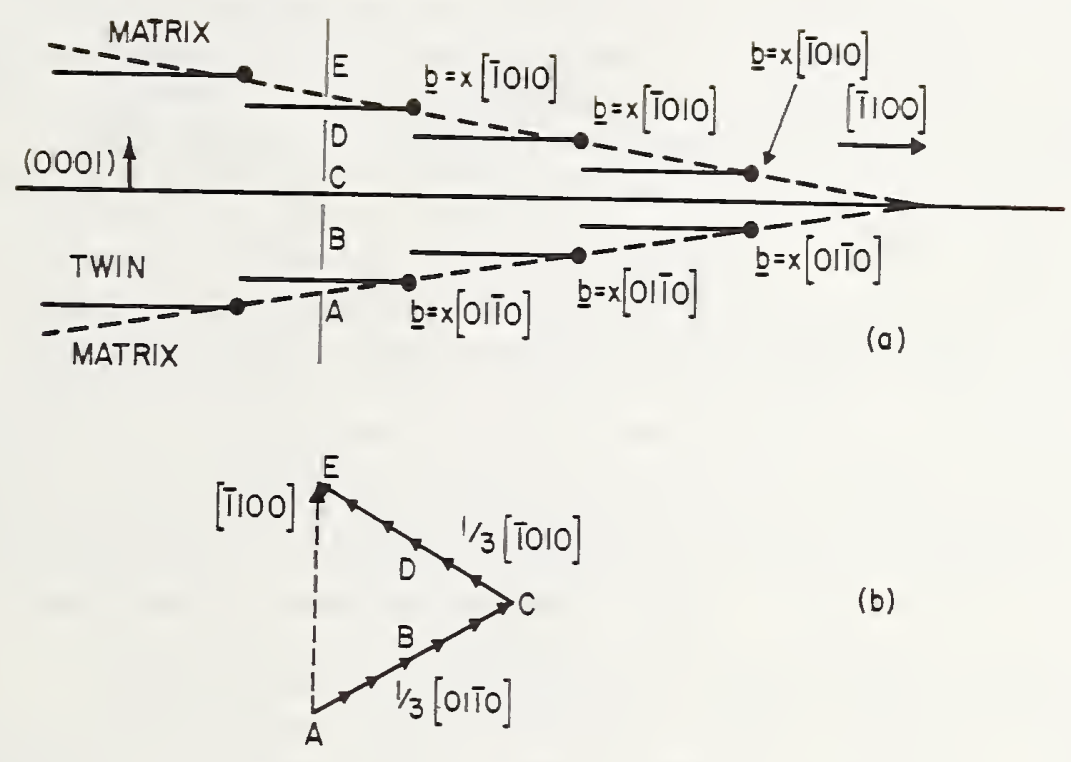

Figure 8. a) Schematic representation of configuration of boundary dislocations at the tip of a symetric wedgeshaped basal twin based on present observations. Twin is viewed parallel to $(0001)$ along [112̄o] direction as in Fig. 6c.

b) Vector diagram illustrating nature of the relative shear displacements on (0001) planes through crosssection of basal twin, e.g., $A B C D E$ in (a).

The significance of the results can be understood by noting that, since the boundary dislocations are glissile on $\{0001\}$, each face of the twin corresponds to a simple shear boundary. The observed structure of the twin boundaries thus directly suggests a twinning mechanism involving uniform shear on (0001) along $\pm[10 \overline{10}]$ above the mid-plane of the twin and along t[0ī10] below the midplane. Such a process is clearly imcompatible with a unidirectional shear process normally used to describe twinning. It is also incompatible with Kronberg's proposed dislocation model for basal twinning [14]. 
The observed structure can, however, be explained on the basis of a different and relatively simple dislocation model for basal twinning. The details of this model are included in a formal treatment of basal twinning which is currently being prepared for publication elsewhere. Only those aspects relating to the present results and adimittedly idealized by Fig. 8 a will be described here.

Basic to this model, is the realization the displacements of $1 / 3[\overline{1} 010], 1 / 3[01 \overline{1} 0]$, or $1 / 3[1 \overline{1} 00], i . e .$, opposite to the macroscopic twinning shear directions, on every other basal lattice plane will result in a twinned structure. As a result, a symmetric twin, whose orientation and boundary displacements are depicted in Fig. 8a, can be described by the passage of 1/3[1010] partial dislocations on every other (0001) lattice plane situated above the mid-plane of the twin and the passage of 1/3[01 lo] partial dislocations on every other (0001) lattice plane below the mid-plane. This process can be envisioned by considering the action of a hypothetical double-ended pole dislocation source emitting $1,3[\overline{1} 010]$ dislocations at one end anc 1/3[01 $\overline{10}$ ] dislocations at the other end under a uniform applied stress. The resulting displacements through any cross-section of the twin, e.g. ABCDE in Fig. 8a, will then be represented by a simple vector diagram, Fig. $8 \mathrm{~b}$. As seen, the relative shear displacements above and below the midplane correspond to the experimentally determined directions (the sign of which cannot be uniquely specified). Moreover, the resultant matrix displacement across the twin is along [11100]. Propagation of the twin through the crystal would thus eventually result in a maximum surface offset along [illoo], which corresponds to the required macroscopic twinning shear direction, $\sigma_{1}$. Since the passage of each $1 / 3[\overline{1} 010]$ and $1 / 3[01 \overline{1} 0]$ dislocations produces a net resolved displacement of $1 / 6[\overline{1} 100]$ on every other (0001) lattice plane, the resultant shear along [ïl00] is simply

$$
\frac{\mid 1 / 6[1100]}{|1 / 6 c|}=\sqrt{3} \mathrm{a} / \mathrm{c} \text {, or } 0.634 \text {, }
$$

which corresponds to the experimentally verified required value.

The proposed model thus satisfies all the macroscopically observed aspects of twinning. Unlike Kronberg's model, the synchonous displacements of adjacent oxygen and aluminum lattice planes in different direction under a uniform stress is not required. Moreover, the resulting twin interface on (0001) is a true mirror plane, not a shear (faulted) interface.

The author wishes to acknowledge the support of the Army

Research office. 


\section{$\underline{\text { References }}$}

[1] B. J. Hockey, J. Am. Ceram. Soc., 54, 223 (1971).

[2] B. J. Hockey, pp. 21-50 in The Science of Hardness Testing and Its Research Applications. Edited by J. H. Westbrook and

H. Conrad. American Society for Metals, Metals Park. Ohio 1973.

[3] International Tables for X-ray Crystallography, Vol. 1; No. 167, p. 275. Kynoch Press, Brimingham, England, 1962.

[4] J. D. Snow and A. H. Heuer, J. Am. Ceram. Soc., 56, 153 (1973).

[5] P. B. Hirsch, A. Howie, R. B. Nicholson, D. W. Pashley, and M. J. Whelan. Electron Microscopy of Thin Crystals. Butterworth, Inc., Washington, D.C., 1965.

[6] J. M. Silcock and W. J. Tunstall, Phil. Mag. 10, 361 (1964).

[7] M. V. Klassen-Neklyudova, V. G. Govorkov, A. A. Urusovskaga, M. N. Voinova, and E. P. Kozlovskaga, Phys. Stat. Solidi, 39, 679 (1970).

[8] M. V. Klassen-Neklyudova, J. Tech. Phys. (USSR), 12, 519, 535 (1942).

[9] R. Scheuplein and P. Gibbs, J. Am. Ceram. Soc., 43, 458 (1960).

[10] D. J. Gooch and G. W. Grokes, J. Am. Ceram. Soc., 55, 105 (1972).

[11] K. Veit, Neues Jahrb. Mineral., Geol. Palaeontol., Beilageband, $\underline{45}, 121$ (1921).

[12] E. Stofel and H. Conrad, Trans. AIME, 227, 1053 (1963).

[13] A. H. Heuer, Phil. Mag., 13, 379 (1966).

[14] M. L. Kronberg, Acta Met., 5, 507 (1957).

[15] B. J. Hockey, Proc. Brit. Ceram. Soc., 20, 95 (1972). 

NBS-114A (REV. 7-73)

\begin{tabular}{|c|c|c|c|}
\hline $\begin{array}{l}\text { U.S. DEPT. OF COMM. } \\
\text { BIBLIOGRAPHIC DATA } \\
\text { SHEET }\end{array}$ & $\begin{array}{l}\text { 1. PUBLICATION OR REPORT NO. } \\
\text { NBSIR-75-764 }\end{array}$ & $\begin{array}{l}\text { 2. Gov't Accession } \\
\text { No. }\end{array}$ & 3. Recipient's Accession No. \\
\hline \multirow{3}{*}{\multicolumn{3}{|c|}{$\begin{array}{l}\text { 4. TITLE AND SUBTITLE } \\
\text { Pyramidal SIip on }\{11 \overline{2} 3\}<\overline{1} 100>\text { and Basal Twinning } \\
\text { In } \mathrm{A}_{2} \mathrm{O}_{3}\end{array}$}} & 5. Publication Date \\
\hline & & & \\
\hline & & & 6. Performing Organization Code \\
\hline \multicolumn{3}{|c|}{ 7. AUTHOR(S) $\quad$ B. J. Hockey } & 8. Performing Organ. Report No. \\
\hline \multirow{2}{*}{\multicolumn{3}{|c|}{$\begin{array}{l}\text { 9. PERFORMING ORGANIZATION NAME AND ADDRESS } \\
\text { NATIONAL BUREAU OF STANDARDS } \\
\text { DEPARTMENT OF COMMERCE } \\
\text { WASHINGTON, D.C. } 20234\end{array}$}} & $\begin{array}{l}\text { 10. Project/Task/Work Unit No. } \\
3130152\end{array}$ \\
\hline & & & 11. Contract/Grant No. \\
\hline \multirow{2}{*}{\multicolumn{3}{|c|}{$\begin{array}{l}\text { 12. Sponsoring Organization Name and Complete Address (Street, City, State, ZIP) } \\
\text { Department of the Army } \\
\text { U. S. Army Research Office } \\
\text { Box CM, Duke Station, Durham, North Carolina } 27706\end{array}$}} & $\begin{array}{l}\text { 13. Type of Report \& Period } \\
\text { Covered }\end{array}$ \\
\hline & & & 14. Sponsoring Agency Code \\
\hline
\end{tabular}

15. SUPPLEMENTARY NOTES

16. ABSTRACT (A 200-word ot less factual summary of most significant in formation. If document includes a significant bibliography or literature survey, mention it here.)

Plastic deformation of $\mathrm{Al}_{2} \mathrm{O}_{3}$ by slip and twinning has been investigated by examining the regions surpounding a microhardness indentation using transmission electron microscopy (TEM). The results establish: (I) the occurrence of pyramidal sIip on $\{11 \overline{2} 3\}\langle\bar{I} 100\rangle$ and (2) the nature of basal twins in this material. The observations on basal twins, in particular, have led to a completely different description for the twinning process, which is briefly described.

17. KEY WORDS (six to twelve entries; alphabetical order; capitalize only the first letter of the first key word unless a proper name; separated by semicolons)

Aluminum oxide; microhardness; plastic deformation; slip; transmission electron microscopy; twinning

\begin{tabular}{|c|c|c|}
\hline 18. AVAILABILITY & $\begin{array}{l}\text { 19. SECURITY CLASS } \\
\text { (THIS REPURT) } \\
\text { UNCL ASSIFIED }\end{array}$ & $\begin{array}{l}\text { 21. NO. OF PAGES } \\
15\end{array}$ \\
\hline $\begin{array}{l}\text { Order From Sup. of Doc., U.S. Government Printing Office } \\
\text { Washington, D.C. 20402, SD Cat. No.C13. }\end{array}$ & $\begin{array}{l}\text { 20. SECURITY CLASS } \\
\text { (THIS PAGE) }\end{array}$ & 22. Price \\
\hline $\begin{array}{l}\square \text { Order From National Technical Information Service (NTIS) } \\
\text { Springfield, Virginia 22151 }\end{array}$ & UNCLASSIFIED & \\
\hline
\end{tabular}



